\title{
FF-10502, an Antimetabolite with Novel Activity on Dormant Cells, Is Superior to Gemcitabine for Targeting Pancreatic Cancer Cells $\mathbf{s}^{\mathbb{\Phi}}$
}

\author{
Shinji Mima, Chihaya Kakinuma, Tamami Higuchi, Kazunori Saeki, Takayuki Yamada, \\ Rena Uematsu, Miki Ishino, Nobuko Kito, Hiroki Nishikawa, Hidenobu Kuniyoshi, \\ Takuya Matsumoto, Hideyasu Fujiwara, Linda J. Paradiso, Yasuhiro Shimada, \\ and Hiroyuki Iwamura
}

FUJIFILM Corporation, Tokyo, Japan (S.M., C.K., T.H., K.S., T.Y., R.U., M.I., N.K., H.N., H.K., T.M., H.F., Y.S., H.I.) and Strategia Therapeutics, Inc., Houston, Texas (L.J.P.)

Received February 23, 2018; accepted April 9, 2018

\begin{abstract}
In this paper, we report that 1-(2-deoxy-2-fluoro-4-thio- $\beta$-Darabinofuranosyl) cytosine (FF-10502), a pyrimidine nucleoside antimetabolite with a chemical structure similar to gemcitabine, shows beneficial anticancer activity via a novel mechanism of action on dormant cells. The growth inhibition of pancreatic cancer cell lines by FF-10502 (IC $50,60-330 \mathrm{nM})$ was moderately weaker than that by gemcitabine in vitro. In contrast, an in vivo orthotopic implantation model in mice with established human pancreatic cancer cell line, SUIT-2, revealed no mortality with FF-10502 intravenous treatment, which was related to regression of implanted tumor and little metastasis, whereas $75 \%$ of the mice treated with gemcitabine died by day 128 . Two in vivo patientderived xenograft models with gemcitabine-resistant pancreatic cancer cells also demonstrated complete tumor growth suppression with FF-10502, but only partial inhibition with gemcitabine.
\end{abstract}

We also investigated the mechanism of action of FF-10502 by using dormant cancer cells, which are reportedly involved in the development of resistance to chemotherapy. In vitro serum starvation-induced dormant SUIT-2 cells developed resistance to gemcitabine even in combination with DNA damage inducers (DDls; $\mathrm{H}_{2} \mathrm{O}_{2}$, cisplatin, and temozolomide). Interestingly, FF-10502 in combination with DDls significantly induced concentrationdependent cell death in accordance with enhanced DNA damage. FF-10502 was far more potent than gemcitabine in inhibiting DNA polymerase $\beta$, which may explain the difference in dormant cell injury, although further investigations for direct evidences are necessary. In conclusion, our study demonstrated the beneficial antitumor effects of FF-10502 in clinically relevant in vivo models, and suggests the importance of preventing DNA repair unlike gemcitabine.

\section{Introduction}

Gemcitabine, an antitumor chemotherapy drug classified as a pyrimidine nucleoside antimetabolite, was approved by the US Food and Drug Administration in 1996 primarily as a result of an enhanced clinical benefit response. The current

Citation of meeting abstracts where the work was previously presented

Shinji M, Hiroki N, Shinichi W, Tamami H, Takeaki S, Hiroyuki I, Chihaya $\mathrm{K}$, Takaaki N, and Yasuhiro S (2017) Abstract \#5127: In vitro and in vivo evaluation of FF-10502-01, a new pyrimidine nucleoside analogue. American Association for Cancer Research (AACR), Washington, DC. April 2017.

Takeaki S, Linda JP, Jill R, Jonathan N, Yoshihide I, Shinji M, Takayuki Y, Chihaya K, Hiroyuki I, and Shinichi W (2017) Abstract \#5112: Evaluation of FF-10502-01, a new pyrimidine nucleoside analogue, in pancreatic (PANC) patient-derived xenograft (PDX) models compared with gemcitabine and in combination with nab-paclitaxel. AACR, Washington, DC. April 2017.

Falchook GS, Bramwell L, Hannan L, Vishwamitra D, Yamada T, Rosner M, Wages D, Myers T, Paradiso L, and Janku F (2017) Abstract CT100: First-inhuman phase 1 trial of pyrimidine anti-metabolite FF-10502-01 in patients with advanced cancer. AACR, Washington, DC. April 2017.

https://doi.org/10.1124/jpet.118.248740.

S This article has supplemental material available at jpet.aspetjournals.org. standard of care for patients with advanced or metastatic pancreatic cancer is gemcitabine-based chemotherapy. However, the antitumor effect of gemcitabine is modest, with a partial response rate of $5.4 \%$ and median survival time 1.3 months longer than that with 5-fluorouracil (5-FU; 4.2 months) (Burris et al., 1997). Following the development of combination therapy with nab-paclitaxel, median survival time was extended by 2.1 months compared with treatment with gemcitabine alone (6.6 months) (Goldstein et al., 2015). Another combination chemotherapy regimen consisting of oxaliplatin, irinotecan, 5-FU, and leucovorin (FOLFIRINOX) also extended the survival, and the median overall survival was 11.1 months in the FOLFIRINOX group as compared with 6.8 months in the gemcitabine group (Conroy et al., 2011). Although these new regimens represent significant improvements, the 5-year survival rate for patients with pancreatic cancer remains only $7 \%$, the lowest among all types of cancer (Siegel et al., 2015). It is especially concerning that a poor prognosis is associated with poor response to chemotherapy and tumor recurrence. Specifically,

ABBREVIATIONS: BER, base excision repair; CSC, cancer stem cell; DDI, DNA damage inducer; dCTP, deoxycytidine triphosphate; dGTP, deoxyguanosine triphosphate; dATP, deoxyadenosine triphosphate; dTTP, deoxythymidine triphosphate; DEAE, Diethylaminoethyl; DMSO, dimethylsulfoxide; EdU, 5-ethynyl-2-deoxyuridine; FBS, fetal bovine serum; FF-10502, 1-(2-deoxy-2-fluoro-4-thio- $\beta$-D-arabinofuranosyl) cytosine; FF-10502-01, FF-10502 methanesulfonate; FF-10502TP, FF-10502-triphosphate; 5-FU, 5-fluorouracil; gemTP, gemcitabine-triphosphate; PBS, phosphate-buffered saline; PDX, patient-derived xenograft; pol $\alpha$, polymerase $\alpha$; pol $\beta$, polymerase $\beta$. 
human pancreatic cancer can acquire resistance to conventional chemotherapeutics, including paclitaxel, 5-FU, cisplatin, and gemcitabine (Arumugam et al., 2009). One such mechanism of drug resistance in pancreatic cancer is the enrichment of dormant cell populations (cancer stem cells and/or nonproliferating, quiescent cells). Stanton et al. (2003) reported that $28 \% \pm 15 \%$ of pancreatic cancer cells were positive for nuclear Ki67 in a study of 33 pancreatic adenocarcinomas, suggesting that over $70 \%$ of pancreatic tumor cells are dormant. Those dormant cells-including cancer stem cells-possess "robustness," a property that encompasses the characteristics of a slow cell cycle, resistance to oxidative stress, and a rapid response to DNA damage, all of which contribute to the development of therapeutic resistance (Yoshida and Saya, 2016). Thus, to advance the treatment of pancreatic cancer, it is necessary to develop novel approaches that target these dormant cells.

FF-10502 [1-(2-deoxy-2-fluoro-4-thio- $\beta$-D-arabinofuranosyl) cytosine], formerly known as $4^{\prime}$-thio-FAC, was discovered by the Yamasa Corporation in Japan and developed as an anticancer chemotherapy drug (Miura et al., 1998). FF-10502 is classified as a pyrimidine nucleoside antimetabolite and has a chemical structure similar to gemcitabine (Fig. 1). FF-10502 has a sulfur atom in its sugar ring instead of oxygen, and has one fluorine atom compared with gemcitabine's two fluorine atoms at the $2^{\prime}$ position in the sugar moiety (Miura et al., 1999). The antiproliferative and cytotoxic effects of FF-10502 have been tested in vitro on many types of solid tumors, including pancreas, lung, stomach, colon, breast, ovary, bladder, melanoma, osteosarcoma, and head and neck cancers (Miura et al., 1998, 1999; Zajchowski et al., 2005). It is noteworthy that FF-10502 has shown superior efficacy compared with gemcitabine in all in vivo studies reported thus far (Miura et al., 1998, 1999, 2002; Zajchowski et al., 2005).

Previous reports have revealed elements of the mechanism of action of FF-10502. After its uptake into cells, FF-10502 is metabolized to FF-10502-triphosphate (FF-10502TP), an active metabolite of FF-10502 similar to gemcitabine-triphosphate (gemTP) (Heinemann et al., 1988). Compared with gemTP, the inhibitory activity of FF-10502TP on DNA polymerase $\alpha(\operatorname{pol} \alpha)$ and polymerase $\beta(\operatorname{pol} \beta)$ was approximately 1000 and 100 times higher, respectively. Therefore, it was hypothesized that the efficacy of FF-10502TP can be attributed to the inhibition of pol $\alpha$ (Miura et al., 2001; Miura and Izuta, 2004). However, this potent inhibition of pol $\alpha$ is not consistent with tumor cell growth inhibition in vitro, as the $\mathrm{IC}_{50}$ values for FF-10502 in tumor cell growth assays are generally higher than those of gemcitabine. This does not explain why FF-10502 has shown efficacy superior to gemcitabine in animal models of tumors in vivo.

To explain the discrepancy between the in vitro and in vivo efficacy of FF-10502 and gemcitabine, we further examined the pharmacological profile of FF-10502, with an objective to elucidate the mechanisms involved. This study focused on pancreatic cancer, because dormancy of this type of tumor has been suggested to be the key factor in the differences in efficacy. The effect of FF-10502 in relation to the inhibition of DNA repair after exposure of dormant cells with chemotherapy resistance to DNA damage inducers (DDIs) and the importance of the novel mechanism involved in the effect are discussed.

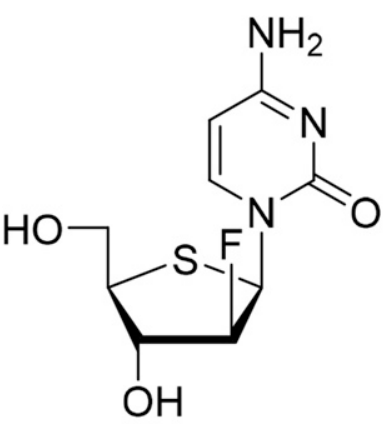

FF-10502

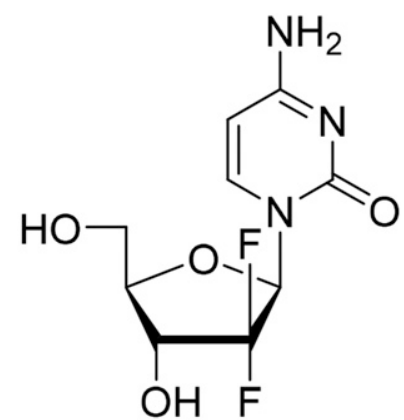

Gemcitabine

(Gemzar $\left.{ }^{\circledR}\right)$

Fig. 1. Chemical structures of FF-10502 and gemcitabine.

\section{Materials and Methods}

Chemicals and Reagents. FF-10502 methanesulfonate (FF10502-01) and FF-10502TP were synthesized and provided by FUJIFILM Corporation (Tokyo, Japan). For simplicity, FF-10502 methanesulfonate is referred to as "FF-10502" in this study. Gemcitabine hydrochloride was purchased from Teva Pharmaceutical Industries (Netanya, Israel) and is designated as "gemcitabine" in this study. The formulation used in the in vivo study represents the free base for both compounds. FF-10502 and gemcitabine were dissolved in phosphate-buffered saline (PBS) for in vitro studies, in dimethylsulfoxide (DMSO) for a combination study with DDIs, or in saline for in vivo studies. GemTP was purchased from Jena Bioscience (Jena, Germany). Three DDIs $\left(\mathrm{H}_{2} \mathrm{O}_{2}\right.$, cisplatin, and temozolomide) were purchased from Kanto Chemical Co., Inc. (Tokyo, Japan); Wako Pure Chemical Industries, Ltd. (Osaka, Japan); and LKT Laboratories, Inc. (St. Paul, MN), respectively. All DDIs were dissolved in culture medium.

Cell Lines. BxPC-3 cells and Capan-1 cells were obtained from the American Type Culture Collection (Manassas, VA), and SUIT-2 cells and MIA PaCa-2 cells were obtained from the Japanese Collection of Research Bioresources (Osaka, Japan). BxPC-3 and SUIT-2 cells were cultured in RPMI 1640 medium (Thermo Fisher Scientific, Waltham, MA) with $10 \%$ heat-inactivated fetal bovine serum (FBS) and 1\% penicillin-streptomycin solution. Capan-1 and MIA PaCa-2 cells were cultured in Iscove's modified Dulbecco's medium (Thermo Fisher Scientific) with $20 \%$ heat-inactivated FBS, and minimum essential medium with $10 \%$ heat-inactivated FBS plus $1 \%$ nonessential amino acids, respectively. All culture media contained $100 \mathrm{units} / \mathrm{ml}$ penicillin and $100 \mu \mathrm{g} / \mathrm{ml}$ streptomycin. The cultures were incubated in a $\mathrm{CO}_{2}$ incubator at $37^{\circ} \mathrm{C}$ with $5 \% \mathrm{CO}_{2}$ in a humidified atmosphere. All cells were subcultured every 3-4 days.

Cell Growth Inhibition Assay. Cells were seeded at 1000 cells/well (BxPC-3, SUIT-2, and MIA PaCa-2) or 3000 cells/well (Capan-1) into 96-well culture plates. After a 24-hour culture, FF-10502, gemcitabine, or PBS alone (control) was added to the wells. The cells were incubated for approximately 72 hours. Cell growth inhibition was evaluated using a CellTiter-Glo Luminescent Cell Viability Assay kit (Promega, Madison, WI). Luminescence was measured using an EnVision plate reader (PerkinElmer, Waltham, MA). The $\mathrm{IC}_{50}$ value of the test substance against cell growth was calculated using Microsoft Office Excel 2003 (Microsoft Corporation, Redmond, WA).

Subcutaneous Implantation Model with Human Pancreatic Cancer Cell Line Capan-1. The experiment was performed in accordance with the Guide for the Care and Use of Laboratory Animals and was approved by the FUJIFILM animal experiment committee. Five-week-old female nude mice (BALB/c-nu/nu) were purchased from CLEA Japan SLC Inc. (Tokyo, Japan). A Capan-1 cell suspension of $1 \times 10^{8}$ cells/ml was prepared with serum-free medium; $100 \mu l$ of the 
cell suspension was subcutaneously injected into the right flank region of each animal. Nine days after implantation, the mice were randomized into nine groups (10 mice/group), and $100 \mu \mathrm{l} / \mathrm{kg}$ of saline (vehicle solution), gemcitabine, or FF-10502 was administered by tail vein injection once weekly for 4 weeks. Tumor diameter and body weight were measured twice weekly. For calculation of tumor volume, both long and short diameters ( $\mathrm{mm}$ ) were measured by a Vernier caliper (Mitutoyo, Kawasaki, Japan). The formula for calculating tumor volume was as follows: tumor volume $\left(\mathrm{mm}^{3}\right)=$ long diameter $(\mathrm{mm}) \times$ short diameter $(\mathrm{mm}) \times$ short diameter $(\mathrm{mm}) \times 0.5$.

Orthotopic Implantation Model with Human Pancreatic Cancer Cell Line SUIT-2. The experiment was performed in accordance with the Guide for the Care and Use of Laboratory Animals and was approved by the FUJIFILM animal experiment committee. Five-week-old female nude mice (BALB/c-nu/nu) were purchased from CLEA Japan SLC Inc. A SUIT-2 cell suspension of $1 \times 10^{8}$ cells $/ \mathrm{ml}$ was prepared in serum-free medium, and $10 \mu \mathrm{l}$ of the cell suspension was injected into the pancreas of each animal under isoflurane anesthesia. After confirmation that there was no hemorrhage at the site of implantation, the abdominal wall incision was closed with absorbable sutures, and the skin was clamped. Seven days after implantation, at which metastases were already observed (Higuchi et al., 2018), the mice were randomized into five groups (20 mice/group), and $100 \mu \mathrm{l} / \mathrm{kg}$ of saline (vehicle solution), gemcitabine, or FF-10502 was administered by tail vein injection once weekly for 18 weeks.

Antitumor activity of the orthotopic implantation model was evaluated by event-free survival time, defined as the day from SUIT-2 cell injection until death or moribundity (e.g., marked decrease in body weight, hypothermia, or other conditions requiring euthanasia). Histopathological evaluation was also performed for various tissues of surviving animals stained with hematoxylin and eosin.

Patient-Derived Xenograft Model. Animal welfare for this experiment complied with the US Department of Agriculture's Animal Welfare Act (9 Code of Federal Regulations Parts 1, 2, and 3), as applicable. Female NOD-SCID mice were purchased from Harlan Laboratories (Indianapolis, IN). Two patient-derived pancreatic cancer cells (PA5364 and PA5365) were used. These are adenocarcinoma and carcinoma cells derived from ascites of a 78-year-old female and the omentum of a 54-year-old female, respectively. PA5364 shows high resistance to 5-FU and carmustine, intermediate resistance to gemcitabine and mitomycin $\mathrm{C}$, and low resistance to cisplatin and doxorubicin in vitro. PA5365 shows high resistance to gemcitabine and doxorubicin; intermediate resistance to ifosfamide and mitomycin $\mathrm{C}$; and low resistance to 5-FU, docetaxel, and SN38 (an active metabolite of irinotecan). The cell suspensions of $2.5 \times 10^{6}$ cell $/ \mathrm{ml}$ (PA5364) or $1.2 \times 10^{6}$ cells/ml (PA5365) were prepared with PBS and mixed with an equal volume of Cultrex extracellular matrix (Trevigen, Gaithersburg, MD), and $200 \mu \mathrm{l}$ of the cell suspension in Cultrex extracellular matrix was injected subcutaneously into the rear flank under isoflurane anesthesia. The animals were randomized into three groups (10 mice/group) when the average tumor size reached approximately $200 \mathrm{~mm}^{3}$. Vehicle (saline), gemcitabine, or FF-10502 was administered by tail vein injection once weekly for 4 weeks, followed by 4 weeks of observation. Animals were monitored weekly for palpable tumors and any changes in appearance or behavior. Once tumors were palpable, they were measured using calipers. For calculation of tumor volume, both long and short diameters $(\mathrm{mm})$ were measured by Vernier caliper (Mitutoyo). The formula for calculating tumor volume was as follows: tumor volume $\left(\mathrm{mm}^{3}\right)=$ long diameter $(\mathrm{mm}) \times$ short diameter $(\mathrm{mm}) \times$ short diameter $(\mathrm{mm}) \times 0.5$.

Inhibitory Activity against Pol $\alpha$ and Pol $\beta$. The inhibitory activity of FF-10502TP and gemTP for pol $\alpha$ was measured by a DNA synthesis assay in vitro (Podust et al., 1989). Purified human pol $\alpha$ (EuRx, Gdansk, Poland) and FF-10502TP or gemTP were incubated for 30 minutes at $37^{\circ} \mathrm{C}$ in $50 \mu \mathrm{l}$ of reaction mixture [60 mM Tris-HCl (pH 8.0); $5.0 \mathrm{mM}$ magnesium acetate; $0.3 \mathrm{mg} / \mathrm{ml}$ bovine serum albumin; $1.0 \mathrm{mM}$ dithiothreitol; $0.1 \mathrm{mM}$ spermine; $20 \mu \mathrm{M}$ each dCTP, dGTP, and dATP; $5 \mu \mathrm{M}\left[{ }^{3} \mathrm{H}\right.$-methyl]dTTP; and $20 \mu \mathrm{g}$ of activated calf thymus DNA]. Likewise, purified human $\operatorname{pol} \beta$ (EuRx) and FF-10502TP or gem TP were incubated for 15 minutes at $37^{\circ} \mathrm{C}$ in $50 \mu \mathrm{l}$ of reaction mixture [50 mM Tris- $\mathrm{HCl}(\mathrm{pH} 8.7) ; 10.0 \mathrm{mM} \mathrm{MgCl} 2 ; 0.4 \mathrm{mg} / \mathrm{ml}$ bovine serum albumin; $1.0 \mathrm{mM}$ dithiothreitol; $100 \mathrm{mM} \mathrm{KCl}$; $15 \%$ glycerol; $50 \mu \mathrm{M}$ each dCTP, dGTP, and dATP; $5 \mu \mathrm{M}\left[{ }^{3} \mathrm{H}\right.$-methyl]dTTP; and $10 \mu \mathrm{g}$ of activated calf thymus DNA]. After incubation, $20 \mu \mathrm{l}$ of the reaction solution was passed through Diethylaminoethyl-cellulose paper, and the membrane was washed with $5 \% \mathrm{Na}_{2} \mathrm{HPO}_{4}(1 \mathrm{ml} \times 6)$, Milli-Q water $(1 \mathrm{ml})$, ethanol $(1 \mathrm{ml} \times 2)$, and diethyl ether $(1 \mathrm{ml})$. The DEAE-cellulose paper was transferred into a scintillation vial and $5 \mathrm{ml}$ of scintillation fluid, and PICO-FLUOR PLUS (PerkinElmer) was added; radioactivity was measured with a liquid scintillation counter (PerkinElmer).

The inhibition rate (individual value) was calculated as 100 - response ratio (formula shown here). In addition, the mean inhibition rate of duplicate samples was calculated:

$$
\text { response ratio: }\left[(\mathrm{B}-\mathrm{N}) /\left(\mathrm{B}_{0}-\mathrm{N}\right)\right] \times 100(\%)
$$

where $\mathrm{B}=$ radioactivity of the sample measuring inhibitory activity (individual value), $\mathrm{B}_{0}=$ radioactivity of the sample measuring total activity (mean value), and $\mathrm{N}=$ radioactivity of the sample measuring nonspecific activity (mean value). For data processing, Microsoft Excel 2003 (Microsoft Corporation) was used.

Inhibitory Activity of DNA Synthesis in a SUIT-2 Orthotopic Implantation Tumor Model. Mice with SUIT-2 orthotopic implantation were prepared in accordance with the procedure described earlier. On day 18, vehicle (saline), gemcitabine, or FF-10502 was administered by tail vein injection $(100 \mu \mathrm{l} / \mathrm{kg})$. The tumors were harvested 4, 24, 48, and 72 hours after drug administration. Mice were injected intraperitoneally with 100-200 $\mu \mathrm{g}$ of 5-ethynyl-2-deoxyuridine (EdU; Baseclick GmbH, Neuried, Germany) in PBS 4 hours before tumor harvest (Salic and Mitchison, 2008). Pieces of the tumor were formalinfixed, embedded in paraffin, and sectioned. After paraffin removal, sections on glass slides were stained with $10 \mu \mathrm{M}$ Alexa568-azide (Thermo Fisher Scientific) for 30 minutes at room temperature. Sections were counterstained with Hoechst 33342 (Thermo Fisher Scientific) and mounted for fluorescence microscopy (CQ1; Yokogawa Electric Corporation, Tokyo, Japan) to quantify the total cell number and DNA synthesizing cell number. The rate of EdU-incorporated cells was calculated as follows:

\section{EdU-incorporated cells $=\mathrm{N}_{\mathrm{E}} / \mathrm{N}_{\mathrm{H}} \times 100(\%)$}

where $\mathrm{N}_{\mathrm{E}}=$ number of EdU-incorporated cells (individual value), and $\mathrm{N}_{\mathrm{H}}=$ number of Hoechst-stained cells (individual value). For data processing, Microsoft Excel 2003 (Microsoft Corporation) was used.

SUIT-2 Dormant Cell Model. SUIT-2 cells were seeded at 15,000 cells/well into 96-well culture plates (CellBIND 96 well clear flat bottom; Corning, Corning, NY) with medium containing 10\% FBS. After a 24-hour culture, the cells were washed twice with $150 \mu \mathrm{l}$ of serum-free medium and then cultured in serum-free medium for 72 hours. FF-10502, gemcitabine, or 0.1\% DMSO alone (control) was added to the wells. $\mathrm{H}_{2} \mathrm{O}_{2}$ (final concentration of $300 \mu \mathrm{M}$ ), temozolomide (final concentration of $200 \mu \mathrm{M}$ ), or cisplatin (final concentration of $5 \mu \mathrm{M}$ ) was also added for combination treatment. The cells were incubated in a $\mathrm{CO}_{2}$ incubator at $37^{\circ} \mathrm{C}$ with $5 \% \mathrm{CO}_{2}$ in a humidified atmosphere for approximately 72 hours, and cell growth inhibition was evaluated using the CellTiter-Glo Luminescent Cell Viability Assay Kit (Promega). Luminescence was measured using an EnVision plate reader (PerkinElmer).

Comet Assay in SUIT-2 Dormant Cell Model. The SUIT-2 cell culture and test article treatments were performed according to the same procedure described earlier, with the exception that SUIT-2 cells were seeded at 100,000 cells/well into 24 -well culture plates and combined with DDIs and FF-10502 or gemcitabine for 4 or 24 hours. After treatment, the cells were detached and resuspended in PBS at over 100,000 cells/ml. The cell suspension was mixed with Comet LMAgarose (Trevigen) and placed onto slides (Matsunami adhesive silane-coated slide, 5 holes; Matsunami Glass Ind., Ltd., Osaka, 
Japan). Cells on the slides were lysed with lysis solution (2.5 M NaCl, $0.1 \mathrm{M}$ EDTA, $0.01 \mathrm{M}$ Tris, $10 \%$ DMSO, and $1 \%$ Triton X-100, $\mathrm{pH} 10$ ) at $4^{\circ} \mathrm{C}$ for at least 30 minutes, and slides were immersed in electrophoresis solution ( $0.3 \mathrm{M} \mathrm{NaOH}, 1 \mathrm{mM}$ EDTA, $\mathrm{pH}>13)$ for 20 minutes. Electrophoresis was then carried out at $21 \mathrm{~V} / \mathrm{cm}$ for 30 minutes. The slides were washed twice with distilled water and immersed in $70 \%$ ethanol, then dried and stained with SYBR Gold (Thermo Fisher Scientific). Fluorescence microscopic images were scored quantitatively by an image analyzer system (Comet Assay IV, version 4.2; Perceptive Instruments Ltd., Edmunds, UK). Percentage of fluorescence intensity in the tail DNA region per whole DNA is expressed as $\%$ tail DNA. The experiment was performed in duplicate, and 60 comet cells/well were analyzed; the mean \% tail DNA was calculated using the Comet Assay Spreadsheet Generator, version 1.3.1 (Perceptive Instruments Ltd.).

Statistical Analysis. Mouse event-free survival was graphically represented using Kaplan-Meier analysis, and was analyzed between groups with the log-rank test using SAS 9.2 (SAS Institute Japan Ltd., Tokyo, Japan) and the interlocking system Exsus version 7.7.1 (CAC EXICARE Corporation, Tokyo, Japan). The patient-derived xenograft (PDX) model was analyzed by one-way analysis of variance and Tukey's test using the GraphPad Prism 5.04 software (GraphPad Software, Inc., La Jolla, CA). In comparison testing, the significance level was set at $5 \%$.

\section{Results}

Antitumor Activity of FF-10502 In Vitro and In Vivo with Human Pancreatic Cancer Cell Lines. The inhibitory activities of gemcitabine and FF-10502 in four human pancreatic cancer cell lines (BxPC-3, SUIT-2, Capan-1, and MIA $\mathrm{PaCa}-2$ ) were evaluated in vitro (Table 1 ). The average $\mathrm{IC}_{50}$ values (nanomolars per liter) of gemcitabine in these cell lines were $17.7,3.7,22.4$, and 27.5 , respectively, and those of FF-10502 were 59.9, 39.6, 68.2, and 331.4, respectively. These results were consistent with those reported in previous studies (Miura et al., 1999; Zajchowski et al., 2005).

The antitumor effect of FF-10502 was evaluated in a mouse xenograft model with the subcutaneously implanted human pancreatic cancer cell line Capan-1. Intravenous administrations of FF-10502 or gemcitabine at $120,240,360$, and $480 \mathrm{mg} / \mathrm{kg}$ once weekly suppressed tumor growth in a dose-dependent manner (Fig. 2, A and B). The maximum decrease in body weight in FF-10502- and gemcitabine-treated mice was $14.5 \%$ at $360 \mathrm{mg} / \mathrm{kg}$ and $28.3 \%$ at $480 \mathrm{mg} / \mathrm{kg}$, respectively. No deaths were observed in either treatment group.

The antitumor effect of FF-10502 was further evaluated in a mouse model of orthotopic implantation with the human pancreatic cell line SUIT-2. The SUIT-2 cell line is derived from liver metastasis of pancreatic cancer patients with Kras and TP53 gene mutations; produces at least two tumor markers, carcinoembryonic antigen and carbohydrate antigen 19-9; and has been widely used since its establishment (Iwamura et al., 1987, 1992; Moore et al., 2001). The SUIT-2 cells can survive in mice after orthotopic implantation, which is known to reproduce the pattern of local tumor growth and distant metastasis observed in human pancreatic cancer (Shono et al., 2001; Higuchi et al., 2018). The first weekly intravenous administration of each dosing solution (20 mice/group) was performed 7 days after implantation, the same day that the implanted SUIT-2 cells began to metastasize to the mesenterium and spleen. Treatments continued until day 128. Vehicle-treated mice started to die at day 19; their survival rate at day 128 (the final day of the study) after tumor
TABLE 1

Cell growth inhibitory activity of FF-10502 and gemcitabine in human pancreatic cancer cell lines

Cells were cultured in the presence of FF-10502 or gemcitabine at concentrations from $0.1 \mathrm{nM}$ to $10 \mu \mathrm{M}$ for 72 hours. Cell viability was determined using the CellTiterGlo Luminescent Cell Viability Assay Kit. Mean $\mathrm{IC}_{50}$ values \pm S.D. are presented for experiments performed at least three times.

\begin{tabular}{lcr}
\hline \multirow{2}{*}{ Cell line } & \multicolumn{2}{c}{$\mathrm{IC}_{50}$} \\
\cline { 2 - 3 } & \multicolumn{1}{c}{$\mathrm{FF}-10502$} & Gemcitabine \\
\cline { 2 - 2 } & $5 M$ & $n M$ \\
\hline BxPC-3 & $59.9 \pm 11.5$ & $17.7 \pm 4.9$ \\
SUIT-2 & $39.6 \pm 0.7$ & $3.7 \pm 0.1$ \\
Capan-1 & $68.2 \pm 2.7$ & $22.4 \pm 1.6$ \\
MIA PaCa-2 & $331.4 \pm 233.8$ & $27.5 \pm 9.8$ \\
\hline
\end{tabular}

implantation was $5 \%$, and median survival was 54.5 days (Fig. 2C; Table 2). Gemcitabine treatment showed a dosedependent and statistically significant prolongation of mouse survival compared with that of vehicle-treated mice. The survival rate at day 128 was $25 \%$ at the $240-\mathrm{mg} / \mathrm{kg}$ dose and $75 \%$ at the $480-\mathrm{mg} / \mathrm{kg}$ dose (Table 2 ). In contrast, all mice treated with 240 or $480 \mathrm{mg} / \mathrm{kg}$ of FF-10502 survived until the end of the study, yielding a survival rate of $100 \%$ at both doses. The effects were statistically significant compared with not only the vehicle-treated group but also the dose-matched gemcitabine-treated group.

A histopathological assessment of five surviving mice in each group revealed further contrast between gemcitabine and FF-10502 treatments (Fig. 2D). Increased sizes of implanted tumors at the pancreas were observed in all gemcitabine-treated mice at 240 and $480 \mathrm{mg} / \mathrm{kg}$. In contrast, all mice treated with FF-10502 at $240 \mathrm{mg} / \mathrm{kg}$ showed regressions of the implanted tumors, and three out of five of the FF-10502-treated mice at $480 \mathrm{mg} / \mathrm{kg}$ showed no implanted tumors. Metastases at the mesenterium were observed in all gemcitabine-treated mice in the $240-\mathrm{mg} / \mathrm{kg}$ group, and in two out of five in the $480-\mathrm{mg} / \mathrm{kg}$ group, whereas metastases were observed after FF-10502 treatment at the same doses in only one out of five mice in each group. Liver metastases were also observed in five out of five and two out of five of the gemcitabine-treated mice at 240 and $480 \mathrm{mg} / \mathrm{kg}$, respectively. However, liver metastases were observed in only one out of five and zero out of five of the FF-10502-treated mice at 240 and $480 \mathrm{mg} / \mathrm{kg}$, respectively.

Antitumor Activity of FF-10502 in Pancreatic Patient-Derived Cancer Cells In Vivo. We next evaluated the antitumor effects of gemcitabine and FF-10502 in a PDX model in vivo, in which two lines of gemcitabineresistant, patient-derived pancreatic tumor cells were used. Four intravenous weekly treatments of gemcitabine or FF-10502 were initiated when the average tumor size reached $200 \mathrm{~mm}^{3}$. The tumors receiving gemcitabine treatment showed slow growth, which turned into rapid growth after the last drug administration on day 22. In contrast, the FF-10502-treated groups showed statistically significant tumor shrinkage at $240 \mathrm{mg} / \mathrm{kg}$, and the effect continued even after the termination of treatment (Fig. 3).

Mechanism of Action of FF-10502. Although the principal mechanisms of FF-10502 antitumor activity remain to be determined, some studies have indicated a potential role of DNA pol $\alpha$ inhibition, an enzyme involved in initiation of DNA replication (Miura et al., 2001; Miura and Izuta, 2004). Miura 
A
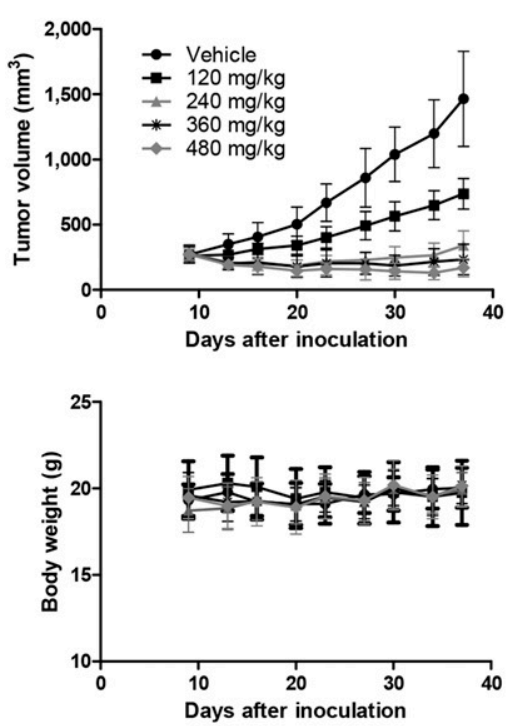

C

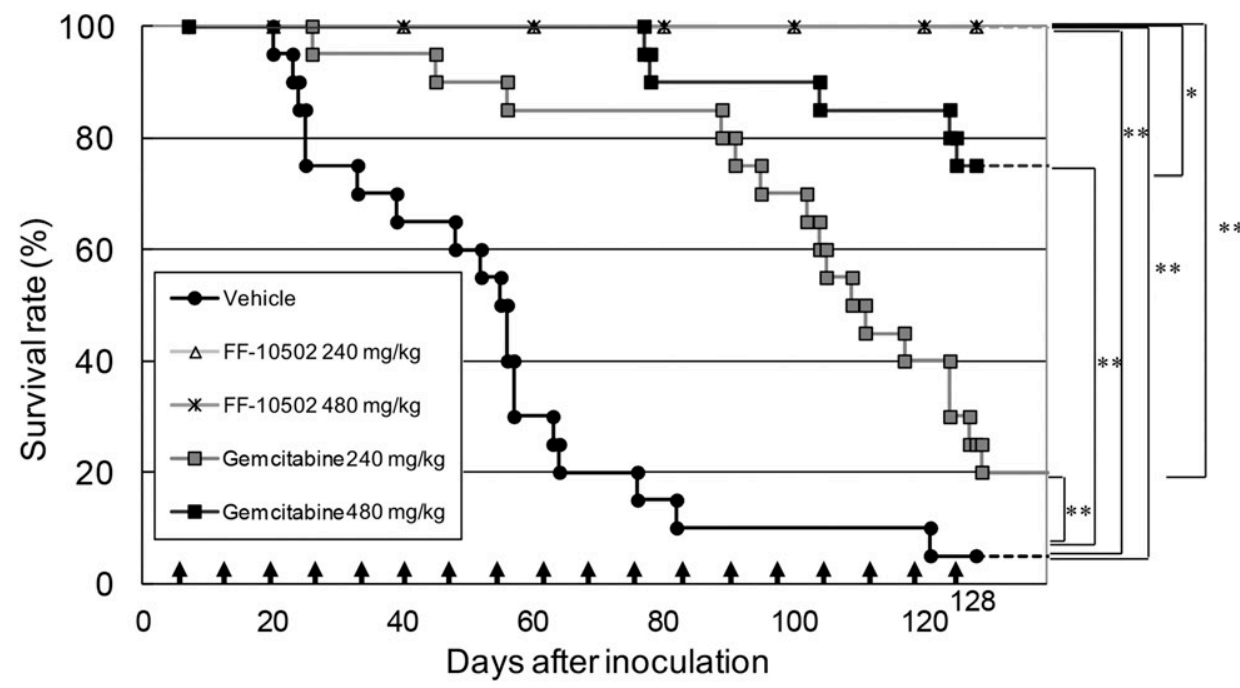

D
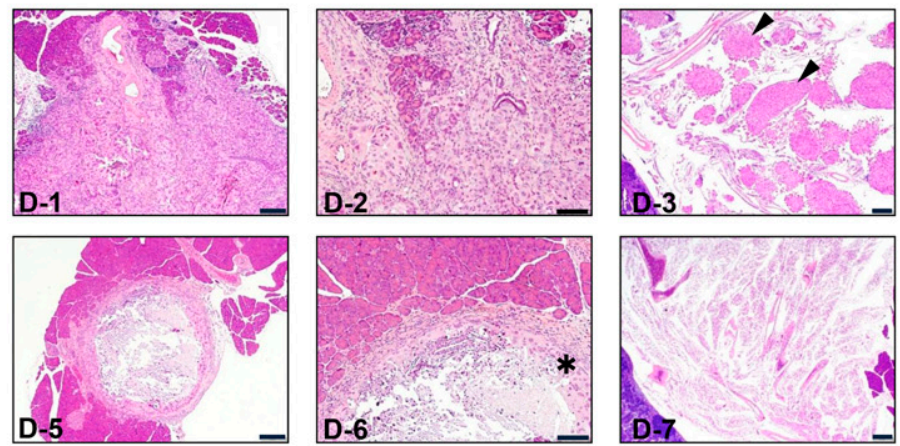

B Gemcitabine
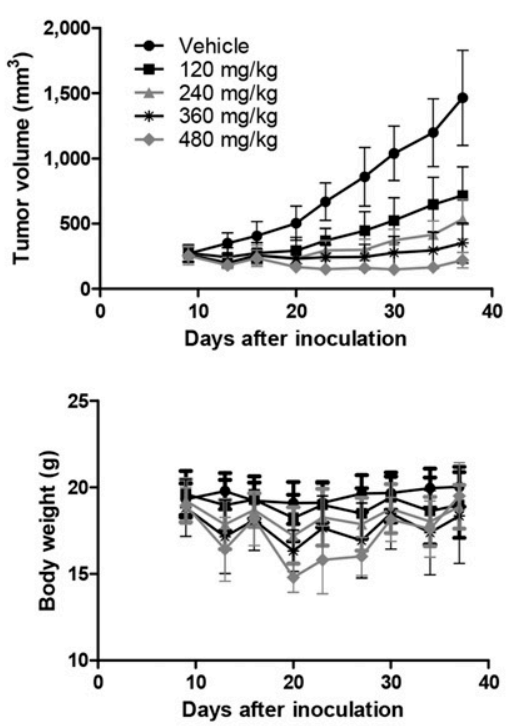
TABLE 2

Summary of SUIT-2 orthotopic implantation model

\begin{tabular}{lccc}
\hline & Dose & Median Survival Time & Number of Animals Surviving at the End of Observation \\
\hline & $m g / k g$ & Days & Surviving Animals $/ n$ \\
Vehicle & - & 54.5 & $1 / 20$ \\
FF-10502 & 240 & $>128^{a}$, & $20 / 20$ \\
FF-10502 & 480 & $>128^{a}, c$ & $20 / 20$ \\
Gemcitabine & 240 & $109^{a}$ & $5 / 20$ \\
Gemcitabine & 480 & $>128^{a}$ & $15 / 20$ \\
\hline
\end{tabular}

${ }^{a} P<0.01$ for each group vs. vehicle.

${ }^{b} P<0.01$ for $240 \mathrm{mg} / \mathrm{kg} \mathrm{FF}-10502$ vs. $240 \mathrm{mg} / \mathrm{kg}$ gemcitabine.

${ }^{c} P<0.05$ for $480 \mathrm{mg} / \mathrm{kg} \mathrm{FF}-10502$ vs. $480 \mathrm{mg} / \mathrm{kg}$ gemcitabine.

dependent on its inhibitory activity for $\operatorname{pol} \alpha$; consequently, we evaluated DNA synthesis activity in tumors using a mouse model of orthotopically implanted SUIT-2 cells by measuring the percentage of EdU incorporated into DNA after FF-10502 or gemcitabine administration. Both FF-10502 and gemcitabine inhibited DNA synthesis from 4 to 48 hours, but DNA synthesis recovered by 72 hours. No significant differences were observed in the inhibitory activities for DNA synthesis between FF-10502 and gemcitabine (Fig. 4, C and D).

We next examined $\operatorname{pol} \beta$, in light of a previous study that reported the potency of FF-10502TP against $\operatorname{pol} \beta$ to be 23 times higher than that of gemTP (Miura et al., 2001). This trend was confirmed in our current study, although gemTP did not reach $50 \%$ inhibition while the $\mathrm{IC}_{50}$ of FF-10502TP was $10 \mu \mathrm{M}$ (Fig. 4B). Pol $\beta$ is known to be a DNA-repairing enzyme that plays a key role in base excision repair (BER); therefore, DDIs causing DNA damage (repaired by BER) were combined with FF-10502 or gemcitabine to investigate whether $\operatorname{pol} \beta$ inhibitory activity contributes to its cytotoxic effect. To avoid antiproliferation effects by pol $\alpha$ inhibition with FF-10502 or gemcitabine, we established a SUIT-2 dormant cell model that was induced by serum-free medium (Fig. 5A). SUIT-2 cells did not proliferate, and cell death was not evident by 72 hours in serum-free conditions. Individual treatment of gemcitabine or FF-10502, or DDIs alone, did not affect cell viability (Fig. 5B). Under these conditions, gemcitabine did not affect, or weakly affected, cell viability in combination with DDIs. However, FF-10502 induced significant cell death in combination with $\mathrm{H}_{2} \mathrm{O}_{2}$, cisplatin, or temozolomide (Fig. 5, C-E). The comet assay was applied to confirm DNA damage; the results clearly indicated that the combination of FF-10502 with DDIs caused synergistic DNA damage, whereas the combination of gemcitabine with DDIs yielded little response (Figs. 6 and 7; Table 3).

\section{Discussion}

In most of the previous studies, FF-10502 was evaluated in mice models of subcutaneously implanted pancreatic cancer cell lines in vivo and showed superior efficacies compared with gemcitabine (Miura et al., 1998, 1999, 2002; Zajchowski et al., 2005). We further evaluated FF-10502 in our study using more clinically relevant models in vivo, i.e., orthotopic implantation of human pancreatic cancer SUIT-2 cells and subcutaneous implantation of gemcitabine-resistant patient-derived cells. The SUIT-2 cell line has been widely used in vitro and in vivo since its establishment from metastasis in livers of human pancreatic patients. The in vivo orthotopic implantation model with SUIT-2 in mice has been validated and shows similarities to human pancreatic patients in terms of metastases at the peritoneum, diaphragm, liver, and lungs, and the partial response to gemcitabine (Tomioka et al., 2001; Higuchi et al., 2018). Our study using the model revealed that FF-10502-treated mice showed prominent inhibition of implanted tumors and little or no hepatic or intraperitoneal metastasis, whereas increased sizes of implanted tumors and metastases were observed in gemcitabine-treated mice (Fig. 2D). The results suggested that these histopathological observations were related to survival of all
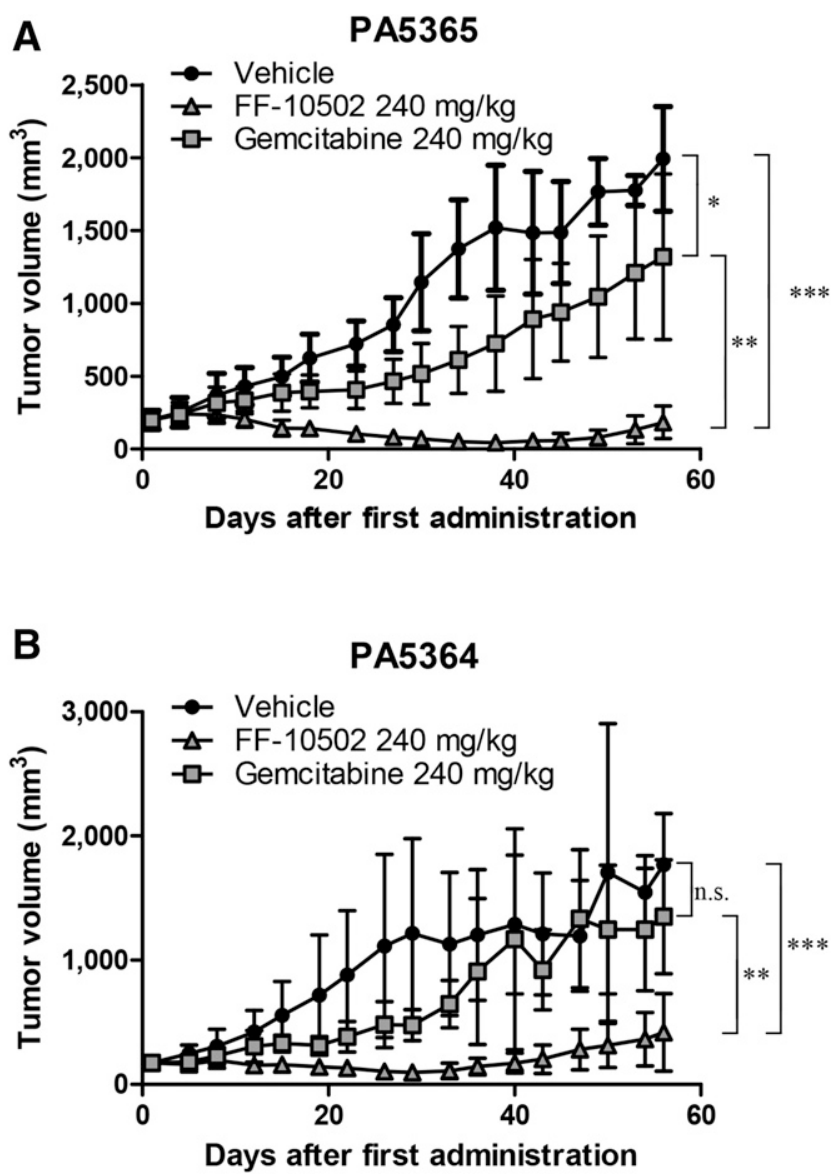

Fig. 3. Antitumor effects of FF-10502 and gemcitabine on two pancreatic PDX models. Patient-derived pancreatic cancer cells from PA5365 cells (A) and PA5364 cells (B) were mixed with Cultrex extracellular matrix and subcutaneously implanted into 10 NOD-SCID mice. When the average tumor size reached approximately $200 \mathrm{~mm}^{3}$, treatment with vehicle (saline), $240 \mathrm{mg} / \mathrm{kg} \mathrm{FF}-10502$, or $240 \mathrm{mg} / \mathrm{kg}$ gemcitabine was initiated and administered intravenously once weekly for 4 weeks. One-way analysis of variance and Tukey's test were applied and significant differences are indicated; $* P<0.05$; $* * P<0.01$; ${ }^{* * *} P<0.005$ between groups. 
A pola

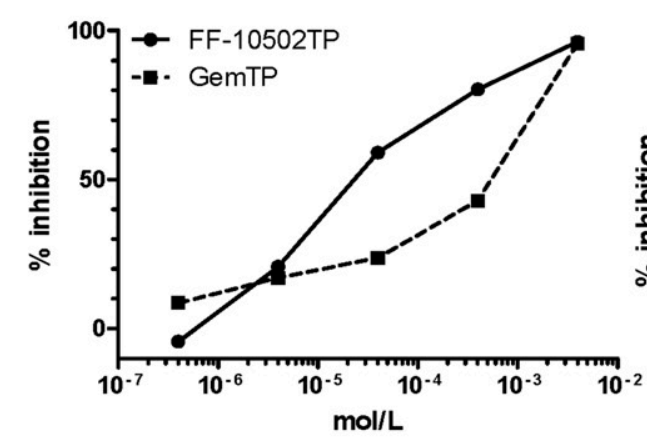

B

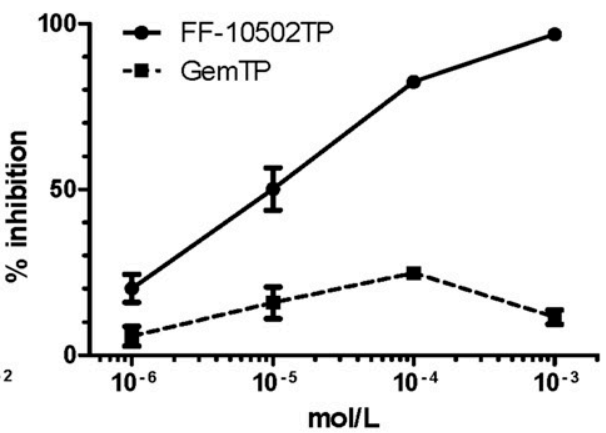

C
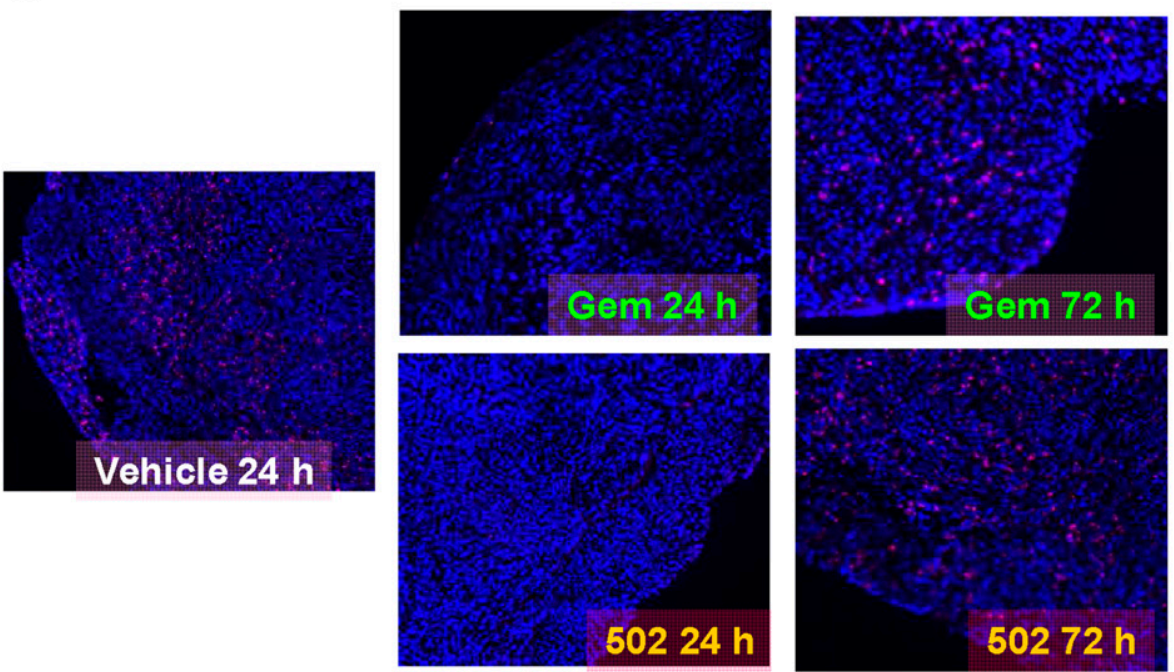

Fig. 4. Inhibitory activity of FF-10502 and gemcitabine on DNA polymerase $\alpha$ and $\beta$. Inhibitory activity of FF-10502TP and gemTP on mammalian pol $\alpha$ at concentrations from 0.4 to $4000 \mu \mathrm{M}(\mathrm{A})$ and $\operatorname{pol} \beta$ at concentrations from 1 to $1000 \mu \mathrm{M}(\mathrm{B})$. Each value represents the average of duplicate determinations. (C) Images of confocal fluorescence microscopy from tumor sections. EdU incorporated into nuclei (purple) and nuclei stained with Hoechst 33342 (blue) are shown for the indicated treatment times. Gem, gemcitabine; 502, FF-10502. (D) Percentage of EdU-incorporated cells counted in three image fields (mean \pm S.D.). Time points were $4,24,48$, and 72 hours. Mice were treated with vehicle (at 24 hours), gemcitabine, or FF-10502.

\section{D}

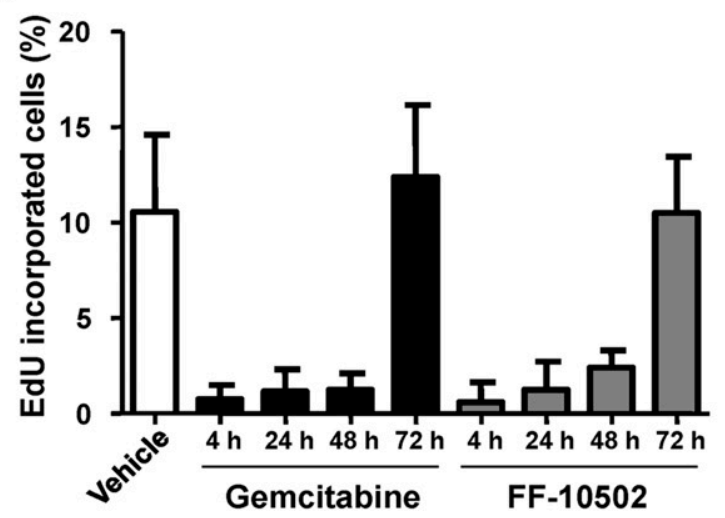

mice treated with FF-10502, unlike gemcitabine (Fig. 2C). The PDX models with pancreatic cancer cells from patients with resistance to gemcitabine also showed clear difference between FF-10502 and gemcitabine (Fig. 3). These are new findings showing the superior efficacy of FF-10502 to gemcitabine in those clinically relevant animal models of pancreatic cancer.

The growth-inhibitory activity of FF-10502 in vitro human pancreatic cancer cell lines (BxPC-3, SUIT-2, Capan-1, and
MIA PaCa-2) was lower than that of gemcitabine (Table 1). However, the antitumor activity of FF-10502 in vivo was superior to that of gemcitabine, as demonstrated in mouse models of Capan-1 xenografts, SUIT-2 orthotopic implantation, and PDX with pancreatic cancer cells in vivo.

We hypothesized that the lower efficacy of gemcitabine in vivo is caused by the presence of slow growth or dormant cells. It is empirically known that implanted cells in vivo grow 
A
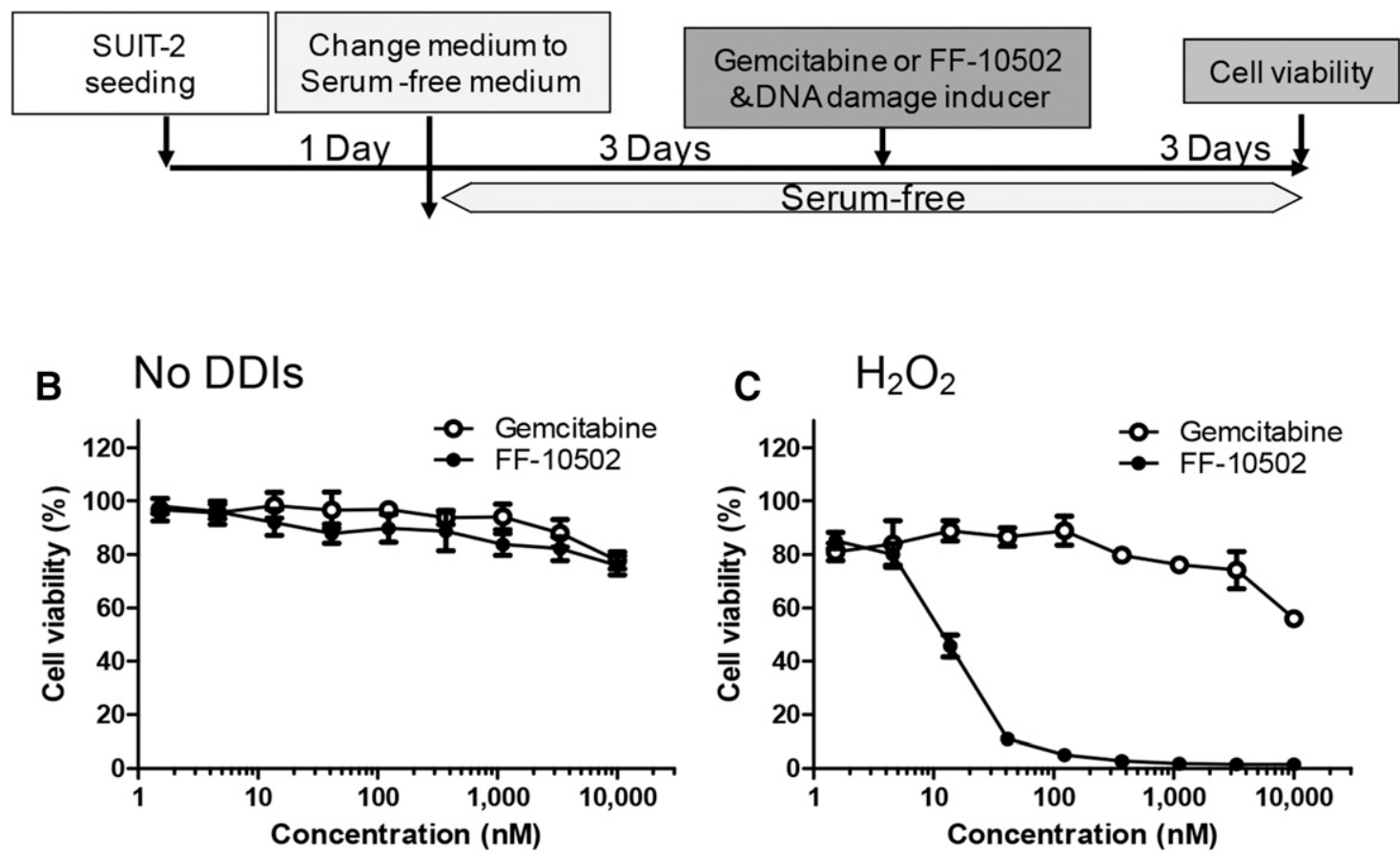

\section{Cisplatin}

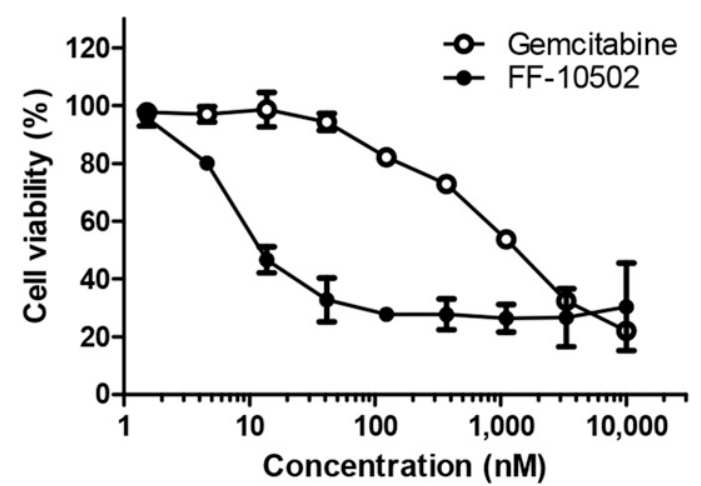

E Temozolomide

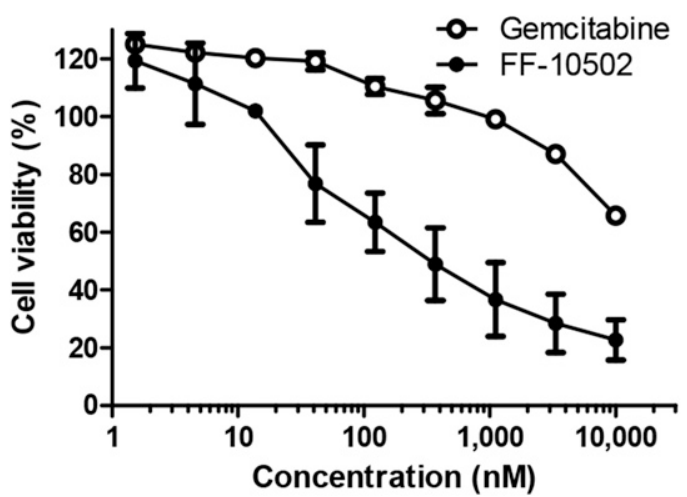

Fig. 5. Cytotoxic effect of DDI treatment in combination with either FF-10502 or gemcitabine on pancreatic cancer dormant cells. (A) Study design of the SUIT-2 dormant cell model. After 3 days of culture in serum-free medium, cells were incubated with FF-10502 or gemcitabine at concentrations from 1 to $10 \mu \mathrm{M}$ in the presence or absence of DDIs for 3 days. The viability of the remaining cells was evaluated by the CellTiter-Glo Luminescent Cell Viability Assay kit. Cell viability was plotted at each concentration of FF-10502 and gemcitabine in the absence of DNA damaging inducers (B) and the presence of $300 \mu \mathrm{M} \mathrm{H}_{2} \mathrm{O}_{2}$ (C), $5 \mu \mathrm{M}$ cisplatin (D), and $200 \mu \mathrm{M}$ temozolomide (E).

much slower than cultured cells in vitro. Amikura et al. (1995) reported that the doubling time of metastatic pancreatic tumor cells in the liver in vivo was approximately 15 times longer than their doubling time in culture. In this study, we demonstrated that $90 \%$ of implanted SUIT-2 cells did not proliferate (Fig. 4, C and D). Gemcitabine is not cytotoxic to cells that grow very slowly or acquire dormancy, since the primary target of gemcitabine is the DNA synthesis enzyme pol $\alpha$. For example, the potency of gemcitabine is approximately 100 times lower in a quiescent Capan-2 spheroid culture than in a proliferative monolayer culture (Dufau et al., 2012). In accordance with this prior report, we demonstrated that gemcitabine did not affect dormant cells cultured in serum-free medium (Fig. 5B). Accordingly, we hypothesized that the higher efficacy of FF-10502 observed in the in vivo model can be attributed to cytotoxicity against slow-growing or dormant cells, which emerge due to acquired heterogeneity in vivo, and that FF-10502 may have an additional unique mechanism of action that is distinct from the mechanism of gemcitabine.

In previous studies also conducted in mice, the pharmacokinetics of FF-10502 and gemcitabine were comparable, and FF-10502 showed a high degree of inhibitory activity against $\operatorname{pol} \alpha$ (Miura et al., 2001; Zajchowski et al., 2005). It was hypothesized, therefore, that the superior antitumor activity of FF-10502 was caused by high pol $\alpha$ inhibitory activity. 


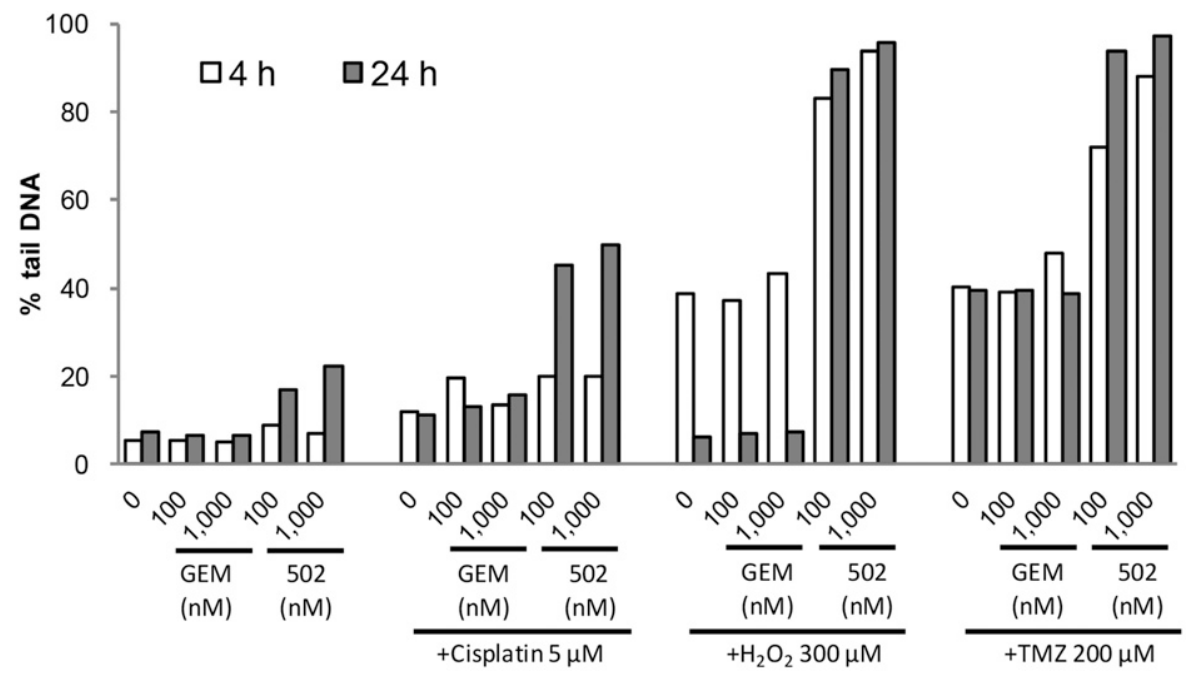

Fig. 6. DNA damage induced by the combination of DDIs with FF-10502 or with gemcitabine was evaluated by a comet assay in SUIT-2 cells under serum starvation. Serum-starved SUIT-2 cells were exposed to FF-10502 or gemcitabine $(100$ or $1000 \mathrm{nM})$ in the presence or absence of DDIs (cisplatin, $\mathrm{H}_{2} \mathrm{O}_{2}$, or temozolomide). After 4 and 24 hours of exposure, cells were subjected to the comet assay as described in Materials and Methods. Results are expressed as the percentage of DNA with comet-like tail (\% tail DNA) and the mean \% tail DNA per 60 comet cells/well is indicated. 502, FF-10502; GEM, gemcitabine; TMZ, temozolomide.

However, there was no significant difference in the inhibition of DNA synthesis between FF-10502 and gemcitabine in the SUIT-2 orthotopic implantation model (Fig. 4, C and D). These results suggest that inhibitory activity against pol $\alpha$ cannot account for the pronounced antitumor activity of FF-10502 in vivo. Thus, we hypothesized that FF-10502 may have additional mechanisms of action.

Although a previous study suggested that FF-10502 did not affect the RNA transcription in the growing cell (Miura et al., 2001), a question was raised as to whether it would be the same in dormant cells. 5-FU is known as a DNA and RNA synthesis inhibitor, and we evaluated the cytotoxicity at $0-100$ $\mu \mathrm{M}$ in our serum starvation assay in combination with $10 \mu \mathrm{M}$ cisplatin. As a result, 5-FU did not affect the cisplatin-induced cytotoxicity even at the highest concentration $(100 \mu \mathrm{M})$
(Supplemental Material). The results suggest that transcriptional inhibition is less likely as the mechanism of action in the enhanced cisplatin-induced cytotoxicity by FF-10502 in dormant cells.

We then focused on $\operatorname{pol} \beta$ inhibitory activity, as FF-10502 showed a much greater degree of inhibition against $\operatorname{pol} \beta$ than gemcitabine (Fig. 4B). The observed inhibition of $\operatorname{pol} \beta$ with FF-10502 was much more prominent in this study than in previous reports. The reason for this difference is not clear, except perhaps differing sources of $\operatorname{pol} \beta$ (calf thymus in the previous report and recombinant human protein in this study). $\mathrm{Pol} \beta$, which is induced by $\mathrm{H}_{2} \mathrm{O}_{2}$ or temozolomide, is a principal DNA polymerase in BER and has been explored as a cancer therapeutic target (Lange et al., 2011; Kim and Wilson, 2012). In previous studies, small-molecule $\operatorname{pol} \beta$ inhibitors
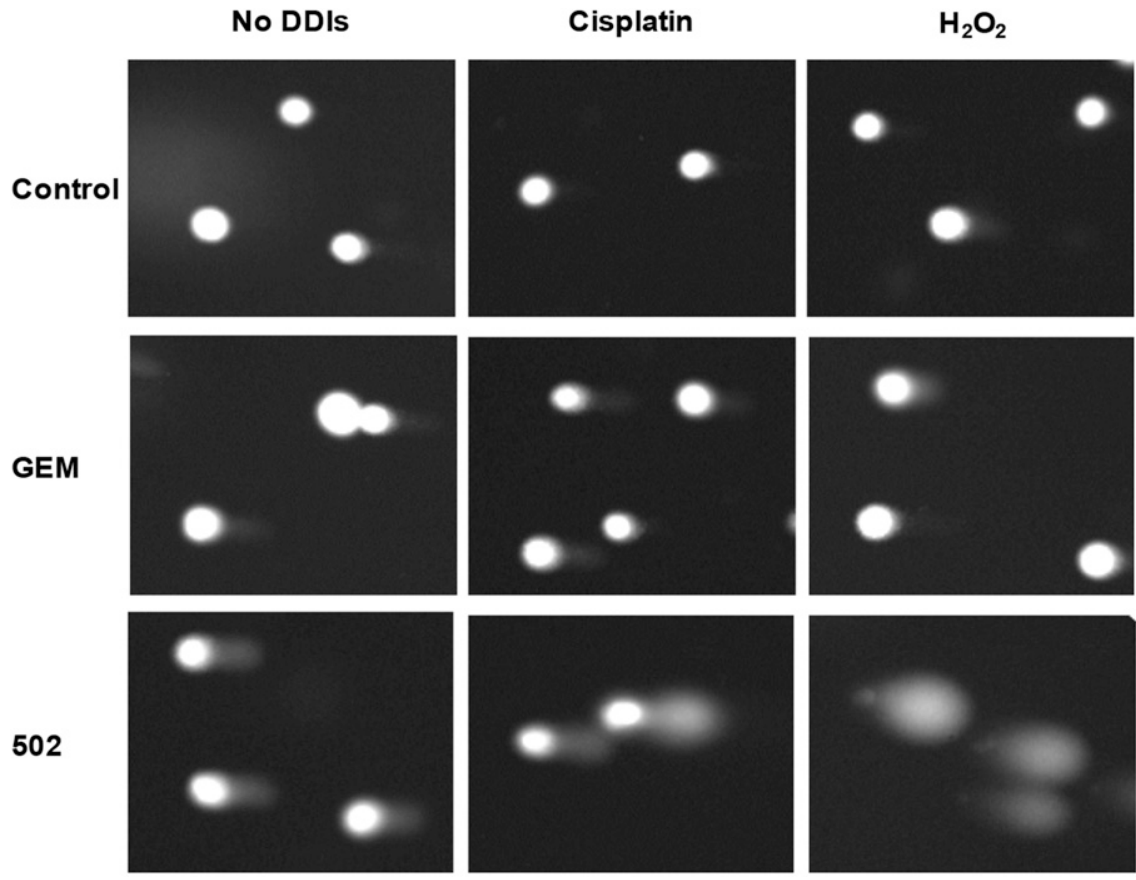

502
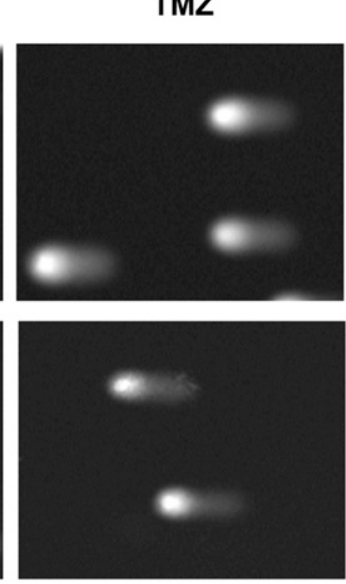

Fig. 7. Representative images in comet assay in combination of DDIs with FF-10502 or gemcitabine at $1000 \mathrm{nM}$ for 24 hours in human pancreatic SUIT2 cells under serum starvation. 502, FF-10502; GEM, gemcitabine; TMZ, temozolomide. 
TABLE 3

Comet assay of DDI treatment in combination with FF-10502 or gemcitabine in human pancreatic SUIT2 cells under serum starvation

Percentage of fluorescence intensity in tail DNA region per whole DNA is expressed as \% tail DNA. The experiment was performed in duplicate, and the mean \% tail DNA was calculated.

\begin{tabular}{|c|c|c|c|c|c|c|c|c|}
\hline \multirow{3}{*}{ Group } & \multicolumn{8}{|c|}{$\%$ Tail DNA } \\
\hline & \multicolumn{2}{|c|}{ No DDIs } & \multicolumn{2}{|c|}{$5 \mu \mathrm{mol} / /$ Cisplatin } & \multicolumn{2}{|c|}{$300 \mu \mathrm{mol} / / \mathrm{H}_{2} \mathrm{O}_{2}$} & \multicolumn{2}{|c|}{$200 \mu \mathrm{mol} / \mathrm{TMZ}$} \\
\hline & $4 \mathrm{~h}$ & $24 \mathrm{~h}$ & $4 \mathrm{~h}$ & $24 \mathrm{~h}$ & $4 \mathrm{~h}$ & $24 \mathrm{~h}$ & $4 \mathrm{~h}$ & $24 \mathrm{~h}$ \\
\hline Vehicle control ( $0.1 \%$ DMSO) & 5.5 & 7.4 & 12.1 & 11.3 & 38.9 & 6.1 & 40.3 & 39.5 \\
\hline $\mathrm{FF}-10502100 \mathrm{nmol} / \mathrm{l}$ & 8.9 & 17.1 & 20.1 & 45.1 & 83.1 & 89.7 & 71.8 & 93.7 \\
\hline $\mathrm{FF}-105021000 \mathrm{nmol} / \mathrm{l}$ & 6.8 & 22.2 & 19.9 & 49.7 & 93.8 & 95.8 & 88.1 & 97.4 \\
\hline Gemcitabine $100 \mathrm{nmol} / \mathrm{l}$ & 5.6 & 6.5 & 19.5 & 13.1 & 37.4 & 6.9 & 39.0 & 39.5 \\
\hline Gemcitabine $1000 \mathrm{nmol} / \mathrm{l}$ & 5.2 & 6.8 & 13.4 & 15.9 & 43.2 & 7.5 & 48.0 & 38.6 \\
\hline
\end{tabular}

TMZ, temozolomide.

enhanced the cytotoxicity of bleomycin or temozolomide in lung and colon cancers (Gao et al., 2008; Jaiswal et al., 2009), and interference in $\operatorname{pol} \beta$ expression increased sensitivity to oxaliplatin (Yang et al., 2010). Therefore, we further investigated the relationship between the inhibitory activity of FF-10502 against $\operatorname{pol} \beta$ and dormant cell viability using a SUIT-2 serum-starvation model. The cell viability of SUIT-2 dormant cells was not affected by treatment with $\mathrm{H}_{2} \mathrm{O}_{2}$ alone, but was dramatically reduced by combining $\mathrm{H}_{2} \mathrm{O}_{2}$ with FF-10502; however, this effect was not observed with gemcitabine (Fig. 5C). Similar results were obtained with temozolomide, which causes DNA damage that is repaired by BER (Fig. 5E). These results suggest that FF-10502 inhibits BER of dormant tumor cells and causes cell death in the presence of DDIs.

It is known that high amounts of reactive oxygen species are generated in tumors and cause DNA damage, such as base oxidation (Szatrowski and Nathan, 1991; Trachootham et al., 2006). Therefore, the high efficacies of FF-10502 in vivo may be explained by endogenous oxidative DNA damage in tumors plus $\operatorname{pol} \beta$ inhibition by FF-10502.

DNA polymerase $\delta$, $\varepsilon$, and $\kappa$, as well as $\operatorname{pol} \beta$, are known to be involved in cisplatin-induced DNA damage (Ogi et al., 2010). The observation that FF-10502 also enhanced the cytotoxicity of cisplatin in dormant cells (Fig. 5D) further suggests that there are other target polymerases for FF-10502.

It may be argued that $\operatorname{pol} \beta$ inhibition causes deleterious effects because of the essential role it plays in BER, but there were no serious toxicities observed with FF-10502 treatment in our animal models, and a clinical trial of FF-10502 that is currently ongoing in the United States has demonstrated good tolerability in patients with solid tumors (Falchook et al., 2017).

Taken together, these results imply that $\operatorname{pol} \beta$ inhibition may play a role in the mechanism contributing to the difference in efficacy between FF-10502 and gemcitabine, although further experiments will be necessary to show direct evidences for the contribution of $\operatorname{pol} \beta$ inhibition as well as the involvement of other DNA polymerases.

Cancer stem cells (CSCs) are accepted as the cause of relapse and distant metastasis in cancer progression (Rasheed et al., 2011; Podberezin et al., 2013; Li and Li, 2014). SUIT-2 cells express CSC markers (CD133+ and CXCR4+) (Moriyama et al., 2010), and our study indicated that orthotopically implanted SUIT-2 cells metastasize aggressively and are resistant to gemcitabine. Despite repeated high-dose administration of gemcitabine $(480 \mathrm{mg} / \mathrm{kg})$, tumor progression was not prevented. In contrast, FF-10502 treatment resulted in no deaths at doses of both 240 and $480 \mathrm{mg} / \mathrm{kg}$; FF-10502 also inhibited dissemination of tumor cells and reduced tumor cell growth at the inoculated site. These results suggest that FF-10502 displays a wide spectrum of antitumor activity that includes targeting rapidly growing and dormant cells (including CSCs); this new insight may encourage the exploration of novel research directions for cancer stem cell therapeutics.

The effect of FF-10502 on the tumor microenvironment such as interactions with immune cells, blood vessels, fibroblasts and extracellular matrix in the process of metastasis should also be considered, however, further investigations are required to clarify the mechanisms.

In conclusion, we demonstrated new findings that FF-10502 is significantly more efficacious than gemcitabine in a variety of clinically relevant mouse models of pancreatic cancer, including PDX models, which may be explained by inhibition of dormant cancer cells through a higher inhibition of $\operatorname{pol} \beta$, unlike gemcitabine. A clinical trial of FF-10502 is currently underway in the United States to assess the usefulness of FF-10502 in patients with solid tumors, including pancreatic tumors. FF-10502 is expected to be a promising agent for pancreatic cancer with acquired resistance to gemcitabine.

\section{Acknowledgments}

We are deeply grateful to Dr. Michihiko Wada and Dr. Junji Furuse for useful suggestions and advice. We thank Takaaki Nakamura, Shin-ichi Watanabe, Takeaki Suzuki, Yuki Awa, Ken Okada, Hiroko Fujisaki, Hiroko Nemoto, Ayako Kamei, and Dr. Thomas Myers for technical assistance and helpful discussion, and Jill Ricono and Jonathan Nakashima for their help in experiments with PDX models.

\section{Authorship Contributions}

Participated in research design: Mima, Kakinuma, Higuchi, Saeki, Yamada, Uematsu, Ishino, Kito, Nishikawa, Paradiso, Iwamura.

Conducted experiments: Mima, Kakinuma, Higuchi, Saeki, Yamada, Uematsu, Ishino, Kito, Nishikawa, Paradiso, Iwamura.

Contributed new reagents or analytic tools: Kuniyoshi, Matsumoto, Fujiwara, Shimada.

Performed data analysis: Mima, Kakinuma, Higuchi, Saeki, Yamada, Uematsu, Ishino, Kito, Nishikawa, Paradiso, Iwamura.

Wrote or contributed to the writing of the manuscript: Mima, Yamada, Paradiso, Iwamura. 


\section{References}

Amikura K, Kobari M, and Matsuno S (1995) The time of occurrence of liver metastasis in carcinoma of the pancreas. Int J Pancreatol 17:139-146.

Arumugam T, Ramachandran V, Fournier KF, Wang $\mathrm{H}$, Marquis L, Abbruzzese JL, Gallick GE, Logsdon CD, McConkey DJ, and Choi W (2009) Epithelial to mesenchymal transition contributes to drug resistance in pancreatic cancer. Cancer Res 69:5820-5828.

Burris HA, III, Moore MJ, Andersen J, Green MR, Rothenberg ML, Modiano MR Cripps MC, Portenoy RK, Storniolo AM, Tarassoff P, et al. (1997) Improvements in survival and clinical benefit with gemcitabine as first-line therapy for patients with advanced pancreas cancer: a randomized trial. J Clin Oncol 15:2403-2413.

Conroy T, Desseigne F, Ychou M, Bouché O, Guimbaud R, Bécouarn Y, Adenis A, Raoul JL, Gourgou-Bourgade S, de la Fouchardière C, et al.; Groupe Tumeurs Digestives of Unicancer; PRODIGE Intergroup (2011) FOLFIRINOX versus gemcitabine for metastatic pancreatic cancer. $N$ Engl J Med 364:1817-1825.

Dufau I, Frongia C, Sicard F, Dedieu L, Cordelier P, Ausseil F, Ducommun B, and Valette A (2012) Multicellular tumor spheroid model to evaluate spatiotemporal dynamics effect of chemotherapeutics: application to the gemcitabine/ CHK1 inhibitor combination in pancreatic cancer. BMC Cancer 12:15.

Falchook GS, Bramwell L, Hannan L, Vishwamitra D, Yamada T, Rosner M, Wages D, Myers T, Paradiso L, and Janku F (2017) Abstract CT100: first-in-human phase 1 trial of pyrimidine anti-metabolite FF-10502-01 in patients with advanced cancer. Cancer Res 77:CT100.

Gao Z, Maloney DJ, Dedkova LM, and Hecht SM (2008) Inhibitors of DNA polymerase beta: activity and mechanism. Bioorg Med Chem 16:4331-4340.

Goldstein D, El-Maraghi RH, Hammel P, Heinemann V, Kunzmann V, Sastre J, Scheithauer W, Siena S, Tabernero J, Teixeira L, et al. (2015) nab-Paclitaxel plus gemcitabine for metastatic pancreatic cancer: long-term survival from a phase III trial. J Natl Cancer Inst 107.

Heinemann V, Hertel LW, Grindey GB, and Plunkett W (1988) Comparison of the cellular pharmacokinetics and toxicity of $2^{\prime}, 2^{\prime}$-difluorodeoxycytidine and 1-beta-Darabinofuranosylcytosine. Cancer Res 48:4024-4031.

Higuchi T, Yokobori T, Naito T, Kakinuma C, Hagiwara S, Nishiyama M, and Asao T (2018) Investigation into metastatic processes and the therapeutic effects of gemcitabine on human pancreatic cancer using an orthotopic SUIT-2 pancreatic cancer mouse model. Oncol Lett 15:3091-3099.

Iwamura T, Katsuki T, and Ide K (1987) Establishment and characterization of a human pancreatic cancer cell line (SUIT-2) producing carcinoembryonic antigen and carbohydrate antigen 19-9. Jpn J Cancer Res 78:54-62.

Iwamura T, Taniguchi S, Kitamura N, Yamanari H, Kojima A, Hidaka K, Setoguchi $\mathrm{T}$, and Katsuki T (1992) Correlation between CA19-9 production in vitro and histological grades of differentiation in vivo in clones isolated from a human pancreatic cancer cell line (SUIT-2). J Gastroenterol Hepatol 7:512-519.

Jaiswal AS, Banerjee S, Panda H, Bulkin CD, Izumi T, Sarkar FH, Ostrov DA and Narayan S (2009) A novel inhibitor of DNA polymerase beta enhances the ability of temozolomide to impair the growth of colon cancer cells. Mol Cancer Res 7:1973-1983.

Kim YJ and Wilson DM, III (2012) Overview of base excision repair biochemistry. Curr Mol Pharmacol 5:3-13.

Lange SS, Takata K, and Wood RD (2011) DNA polymerases and cancer. Nat Rev Cancer 11:96-110.

Li S and Li Q (2014) Cancer stem cells and tumor metastasis (Review). Int J Oncol 44:1806-1812.

Miura S, Endo Y, Yoshimura Y, Endo M, Yonemura Y, and Sasaki T (2002) Potent antitumor effect of 1-(2-deoxy-2-fluoro-4-thio-beta-D-arabinofuranosyl)cytosine on peritoneal dissemination models of gastrointestinal cancers. Oncol Rep 9:1319-1322.

Miura S and Izuta S (2004) DNA polymerases as targets of anticancer nucleosides. Curr Drug Targets 5:191-195.

Miura S, Yoshimura Y, Endo M, Machida H, Matsuda A, Tanaka M, and Sasaki T (1998) Antitumor activity of a novel orally effective nucleoside, 1-(2-deoxy-2-fluoro4-thio-beta-D-arabinofuranosyl)cytosine. Cancer Lett 129:103-110.
Miura S, Yoshimura Y, Endo M, Satoh H, Machida H, and Sasaki T (1999) Comparison of 1-(2-deoxy-2-fluoro-4-thio-beta-D-arabinofuranosyl)cytosine with gemcitabine in its antitumor activity. Cancer Lett 144:177-182.

Miura S, Yoshimura Y, Satoh H, and Izuta S (2001) The antitumor mechanism of 1-(2-deoxy-2-fluoro-4-thio-beta-D-arabinofuranosyl)-cytosine: effects of its triphosphate on mammalian DNA polymerases. Jpn J Cancer Res 92:562-567.

Moore PS, Sipos B, Orlandini S, Sorio C, Real FX, Lemoine NR, Gress T, Bassi C Kloppel G, Kalthoff H, et al. (2001) Genetic profile of 22 pancreatic carcinoma cell lines. Analysis of K-ras, p53, p16 and DPC4/Smad4. Virchows Arch 439:798-802. Moriyama T, Ohuchida K, Mizumoto K, Cui L, Ikenaga N, Sato N, and Tanaka M (2010) Enhanced cell migration and invasion of CD133+ pancreatic cancer cells cocultured with pancreatic stromal cells. Cancer 116:3357-3368.

Ogi T, Limsirichaikul S, Overmeer RM, Volker M, Takenaka K, Cloney R, Nakazawa Y, Niimi A, Miki Y, Jaspers NG, et al. (2010) Three DNA polymerases, recruited by different mechanisms, carry out NER repair synthesis in human cells. Mol Cell 37: 714-727.

Podberezin M, Wen J, and Chang CC (2013) Cancer stem cells: a review of potential clinical applications. Arch Pathol Lab Med 137:1111-1116.

Podust VN, Lavrik OI, Nasheuer HP, and Grosse F (1989) DNA polymerase alphaDNA primase from human placenta. Immunoaffinity purification and preliminary characterization. FEBS Lett 245:14-16.

Rasheed ZA, Kowalski J, Smith BD, and Matsui W (2011) Concise review: emerging concepts in clinical targeting of cancer stem cells. Stem Cells 29:883-887.

Salic A and Mitchison TJ (2008) A chemical method for fast and sensitive detection of DNA synthesis in vivo. Proc Natl Acad Sci USA 105:2415-2420.

Shono M, Sato N, Mizumoto K, Maehara N, Nakamura M, Nagai E, and Tanaka M (2001) Stepwise progression of centrosome defects associated with local tumor growth and metastatic process of human pancreatic carcinoma cells transplanted orthotopically into nude mice. Lab Invest 81:945-952.

Siegel RL, Miller KD, and Jemal A (2015) Cancer statistics, 2015. CA Cancer J Clin 65:5-29.

Stanton KJ, Sidner RA, Miller GA, Cummings OW, Schmidt CM, Howard TJ, and Wiebke EA (2003) Analysis of Ki-67 antigen expression, DNA proliferative fraction, and survival in resected cancer of the pancreas. Am J Surg 186:486-492.

Szatrowski TP and Nathan CF (1991) Production of large amounts of hydrogen peroxide by human tumor cells. Cancer Res 51:794-798.

Tomioka D, Maehara N, Kuba K, Mizumoto K, Tanaka M, Matsumoto K, and Nakamura $\mathrm{T}$ (2001) Inhibition of growth, invasion, and metastasis of human pancreatic carcinoma cells by NK4 in an orthotopic mouse model. Cancer Res 61:7518-7524.

Trachootham D, Zhou Y, Zhang H, Demizu Y, Chen Z, Pelicano H, Chiao PJ, Achanta G, Arlinghaus RB, Liu J, et al. (2006) Selective killing of oncogenically transformed cells through a ROS-mediated mechanism by beta-phenylethyl isothiocyanate. Cancer Cell 10:241-252.

Yang J, Parsons J, Nicolay NH, Caporali S, Harrington CF, Singh R, Finch D, D'Atri S, Farmer PB, Johnston PG, et al. (2010) Cells deficient in the base excision repair protein, DNA polymerase beta, are hypersensitive to oxaliplatin chemotherapy. Oncogene 29:463-468.

Yoshida GJ and Saya H (2016) Therapeutic strategies targeting cancer stem cells. Cancer Sci 107:5-11.

Zajchowski DA, Biroc SL, Liu HL, Chesney SK, Hoffmann J, Bauman J, Kirkland T, Subramanyam B, Shen J, Ho E, et al. (2005) Anti-tumor efficacy of the nucleoside analog 1-(2-deoxy-2-fluoro-4-thio-beta-D-arabinofuranosyl) cytosine (4'-thio-FAC) in human pancreatic and ovarian tumor xenograft models. Int J Cancer 114:1002-1009.

Address correspondence to: Dr. Hiroyuki Iwamura, Pharmaceutical Products Division, FUJIFILM Corporation, 7-3 Akasaka 9-Chome, Minatoku, Tokyo 107-0052, Japan. E-mail: hiroyuki.iwamura@fujifilm.com 